\title{
Effect of polyhedral-oligomeric-sil-sesquioxanes on thermal and mechanical behavior of SC-15 epoxy
}

\author{
I. K. Jones ${ }^{1}$, Y. X. Zhou ${ }^{*}$, S. Jeelani ${ }^{1}$, J. M. Mabry² \\ 1'Tuskegee University's Center for Advanced Materials, Tuskegee, AL 36088, USA \\ ${ }^{2}$ Air Force Research Laboratory, Edwards AFB, CA 93524, USA
}

Received 4 March 2008; accepted in revised form 10 May 2008

\begin{abstract}
In this study, thermal and mechanical properties of nanocomposites containing SC-15 epoxy resin and polyhedral-oligomeric-sil-sesquioxanes (POSS) have been studied. Dynamic Mechanical Analysis (DMA) results show that the addition of $5 \mathrm{wt} \%$ of POSS yielded a $13 \%$ increase in the storage modulus and a $16^{\circ} \mathrm{C}$ enhancement in $T_{g}$. Thermo gravimetric Analysis (TGA) results show that the thermal stability of epoxy increased with higher POSS content. Tension tests were used to evaluate the mechanical properties of materials. Both modulus and tensile strength are linear functions of POSS content. Scanning Electric Microscopy (SEM) pictures of fracture surfaces show that the roughness of the fracture surfaces of epoxy increased after adding POSS. Based on experiment results, a three-parameter nonlinear constitutive equation was developed to describe the strain-softening stress-strain relationship behavior of materials. The parameters in this model are the elastic modulus, a strain exponent, $m$, and a compliance factor, $\beta$. Their relationships to the POSS weight fraction were obtained from the experiment results. The simulated stress-strain curves from the model agree with the test data. Analysis of the model shows that both the strain exponent, $m$, which controls the strain softening and hardening effect of the material, and the compliance parameter, $\beta$, which controls the flow stress level of the material, increase with higher POSS content.
\end{abstract}

Keywords: nanocomposite, epoxy, POSS, thermal and mechanical properties

\section{Introduction}

Epoxy resin has been important to the engineering field for many years. Components made of epoxybased materials provide outstanding mechanical and thermal properties. Using an additional phase, such as inorganic fillers, to strengthen epoxy resins has become a common practice. Because microscale fillers have been successfully synthesized with epoxy resin [1-5], nanoparticle-filled resins are attracting considerable attention; they can enhance properties sometimes even better than conventional filled polymers at volume fractions between $1 \%$ and 5\%. Adding small amounts of nanoparticles $(<5 \mathrm{wt} \%)$ to a matrix system can increase thermal, mechanical, and electrical properties without com- promising the weight or processability of the composite. Consequently, many automotive, aerospace, electronics, and biotechnology companies have shown interest in nanocomposite materials [6-11]. The extremely high surface area of nanocomposites is one of its most attractive characteristics because it helps create a great interface in a composite. According to Reynaud et al. [12], an interface of $1 \mathrm{~nm}$ thick makes up roughly $0.3 \%$ of the total polymer's volume in microparticle-filled composites, whereas it can reach $30 \%$ of the total volume in nanocomposites.

The primary objective of this paper is to determine the effect of adding polyhedral-oligomeric-silsesquioxanes (POSS) on the thermal and mechani-

*Corresponding author, e-mail: yzhou@tuskegee.edu

(c) BME-PT and GTE 
cal properties of epoxy. POSS is inorganic silicalike nanocages $1.5 \mathrm{~nm}$ in size that have organic substituents (as shown in Figure 1). Inactive organic substituents make POSS physically compatible with relevant polymers and promote dispersion in the polymer at a molecular level [13], while substituents that are reactive promote curing or grafting reactions [14]. Thermoplastics such as polypropylene $[15,16]$, polycarbonate $[17,18]$, and polyamide $[19,20]$, and thermosets such as epoxy $[21,22]$ have been reinforced with POSS. Previous results indicate that adding POSS to a matrix system can increase thermal and mechanical properties [23-26].

In this study, POSS was mixed into epoxy with different weight fractions. Tensile tests were performed to evaluate mechanical performance. Thermogravimetric Analysis (TGA) and Dynamic Mechanical Analysis (DMA) were used to evaluate thermal performances. Based on experiment results, a nonlinear constitutive equation was developed to describe the stress-strain relationship of the materials.

\section{Experiment}

\subsection{Materials and manufacturing nanocomposites}

The resin used in this study is a commercially available SC-15 epoxy obtained from Applied Poleramic, Inc. It is a low-viscosity, two-phased, toughened epoxy resin system consisting of part A (resin mixture of diglycidylether of bisphenol-A, aliphatic diglycidlether epoxy toughener) and part B (hardener mixture of cycloaliphatic amine and polyoxylalkylamine). The EpoxyCyclohexyl

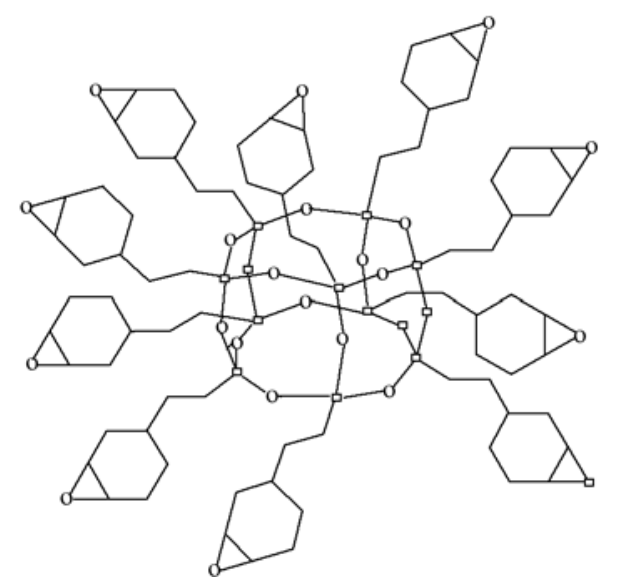

Figure 1. EpoxyCyclohexyl POSS $\left(\mathrm{C}_{8} \mathrm{H}_{13} \mathrm{O}_{2}\right)_{\mathrm{n}}\left(\mathrm{SiO}_{1.5}\right)_{\mathrm{n}}$
POSS was obtained from Hybrid Plastics. The chemical structure is shown in Figure 1. The average epoxy functionality of EpoxyCyclohexyl POSS is 10. POSS molecules are similar to the smallest silica particles. However, unlike silica or modified clays, each POSS molecule contains covalently bonded reactive functionalites suitable for polymerization or for grafting POSS monomers to polymer chains. Some other POSS molecule also contains nonreactive organic functionalities for solubility and compatibility with various polymer systems. But no nonreactive organic functionalities were attached in EpoxyCyclohexyl POSS.

POSS and part A were carefully weighed and mixed together using a magnetic stirring for 24 hours at $800 \mathrm{rpm}$ and $40^{\circ} \mathrm{C}$. The weight fractions of POSS ranged from 1 to $5 \mathrm{wt} \%$. Next, part B was added to the modified part A and mixed using a high-speed mechanical stirrer for about 5 minutes. The mix-ratio of part A and part B of SC-15 was 10:3. The rigorous mixing of part $A$ and part $B$ produced highly reactive volatile vapor bubbles during the initial stages of the reaction, which could detrimentally affect the final product by creating voids. A high vacuum was applied for about 30 minutes, using the Brand Tech Vacuum system. After the bubbles were completely removed, the mixture was transferred into a teflon-coated, dogbone-shaped metal mold and stored for 24 hours at room temperature. The cured material was then de-

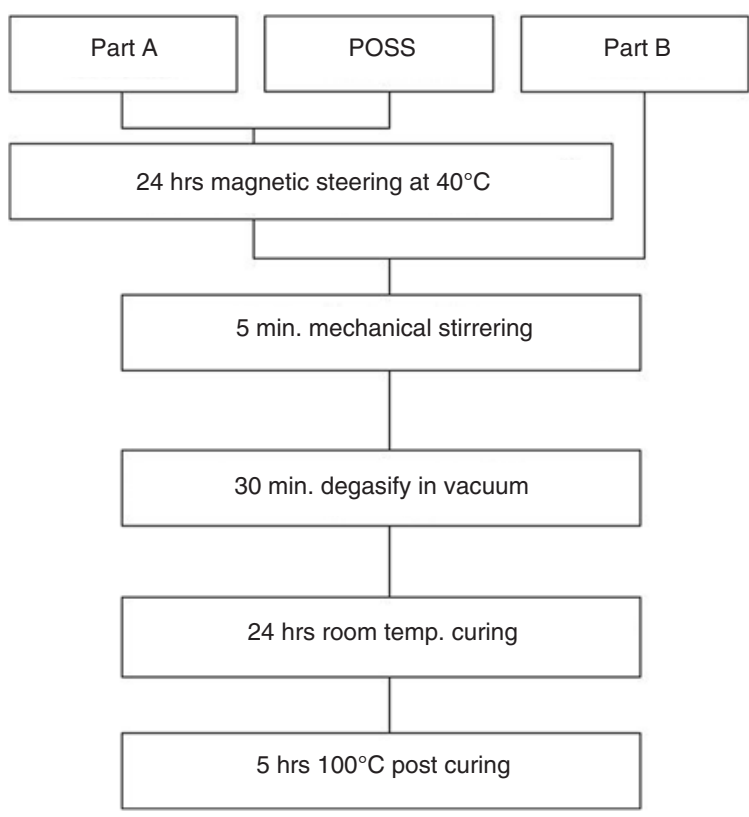

Figure 2. Manufacturing processing of POSS/epoxy nanocomposites 
molded and trimmed. Finally, test samples were machined for thermal and mechanical characterization. All panels were post-cured at $100^{\circ} \mathrm{C}$ for 5 hours. Figure 2 shows the block diagram for manufacturing POSS/epoxy nanocomposites.

\subsection{Test procedure}

Dynamic mechanic analysis (DMA) was performed on a TA Instruments 2980 operating in the threepoint bending mode at an oscillation frequency of $1 \mathrm{~Hz}$. Data were collected from room temperature to $160^{\circ} \mathrm{C}$ at a scanning rate of $3^{\circ} \mathrm{C} /$ minute. The sample specimens were cut into rectangular bars, $1.7 \mathrm{~mm} \times 30 \mathrm{~mm} \times 10 \mathrm{~mm}$, with a diamond saw. Thermogravimetric analysis (TGA) was conducted using a TA Instruments TGA 2950 at a heat rate of $10^{\circ} \mathrm{C} /$ minute from ambient to $800^{\circ} \mathrm{C}$. The TGA samples were cut into small pieces using an ISOMET cutter and were machined to maintain the sample weight of about $10 \mathrm{mg}$, using a mechanical grinder. These samples were put in ceramic crucibles and placed inside the apparatus. The realtime characteristic curves were generated by Universal Analysis 2000-TA Instruments Inc., a data acquisition system.

Tensile testing on the dogbone-shaped specimens was performed according to ASTM Standard D 638-89. Five replicate specimens from four different materials were tested. All tests were performed at room temperature. The test was performed under displacement control mode at a crosshead speed of $2.0 \mathrm{~mm} / \mathrm{min}$ and a strain rate of $0.5 / \mathrm{min}$. Two parameters, elastic modulus $(E)$ and ultimate tensile strength $\left(\sigma_{b}\right)$, were evaluated from each stressstrain curve.

\section{Results and discussions}

\subsection{Thermal properties}

The DMA plots in Figure 3 show storage modulus versus temperature as a function of POSS loading. Storage modulus steadily increases with increasing POSS weight percent. The addition of $5 \mathrm{wt} \%$ of POSS yielded a $13 \%$ increase in the storage modulus at $30^{\circ} \mathrm{C}$. POSS is a rigid body; an increase in POSS concentration increases the rigidity of the composite system. Figure 4 shows loss factor versus temperature curves of POSS/epoxy nanocomposites. As POSS content increases, the tan $\delta$ peaks

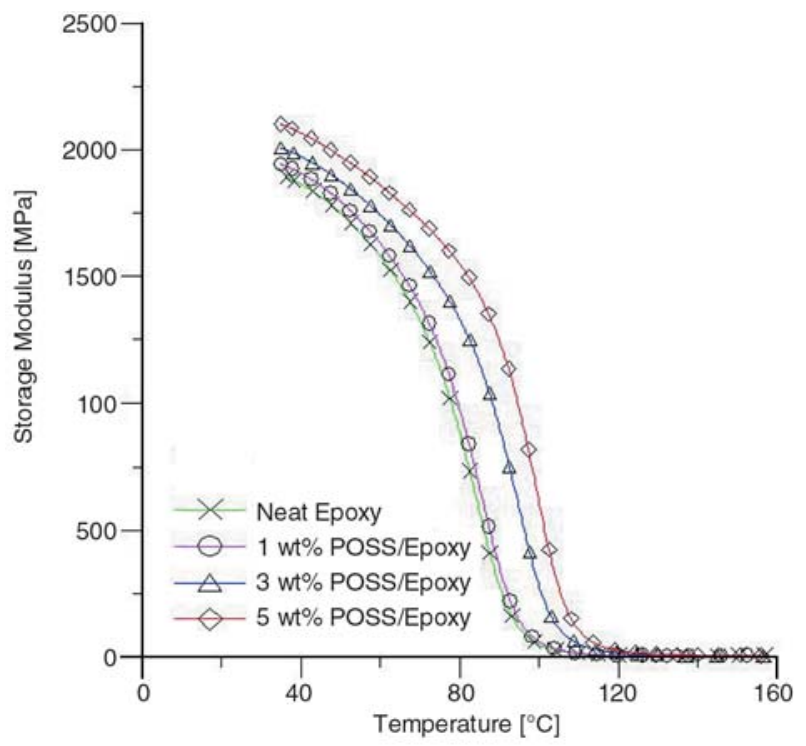

Figure 3. Storage modulus versus temperature plots of POSS/epoxy nanocomposites

of nanocomposites significantly shift to a higher temperature while the widths of tan $\delta$ peaks remarkably broaden and their intensities lower. An increase of $16^{\circ} \mathrm{C}$ in $T_{g}$ was observed in $5 \mathrm{wt} \%$ POSS/epoxy as compared with neat epoxy. According to Huang et al. [27], incorporating POSS increases the crosslinking density of resulting nanocomposites. The increase in crosslinking density leads to high $T_{g}$, broad tan $\delta$ peaks, and high storage modulus.

Another important characteristic of polymers is their stability at high temperatures. Thermogravimetric analysis (TGA) was used to estimate the thermal stability of POSS/epoxy nanocomposites.

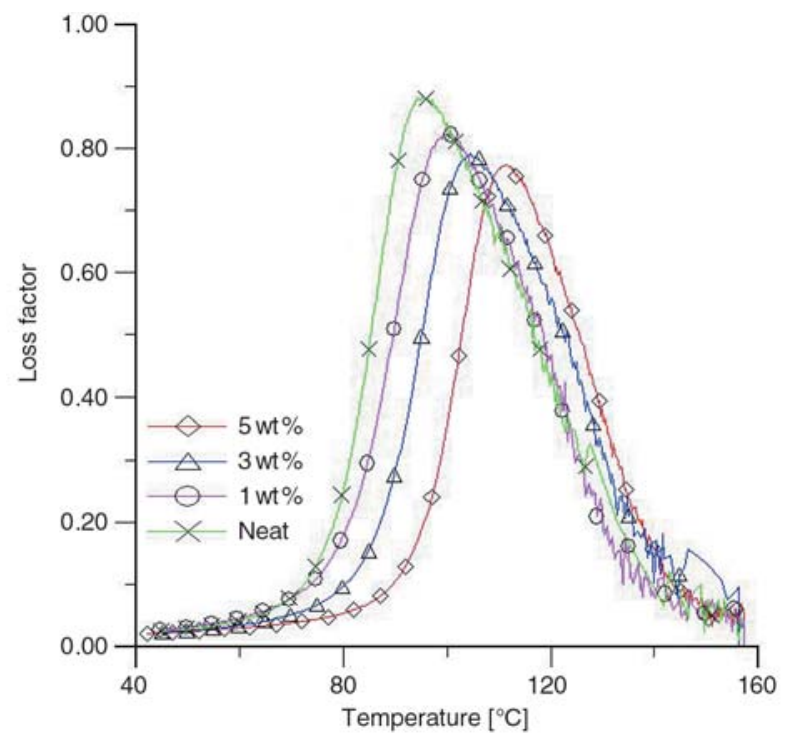

Figure 4. Loss factor versus temperature plots of POSS/epoxy nanocomposites 


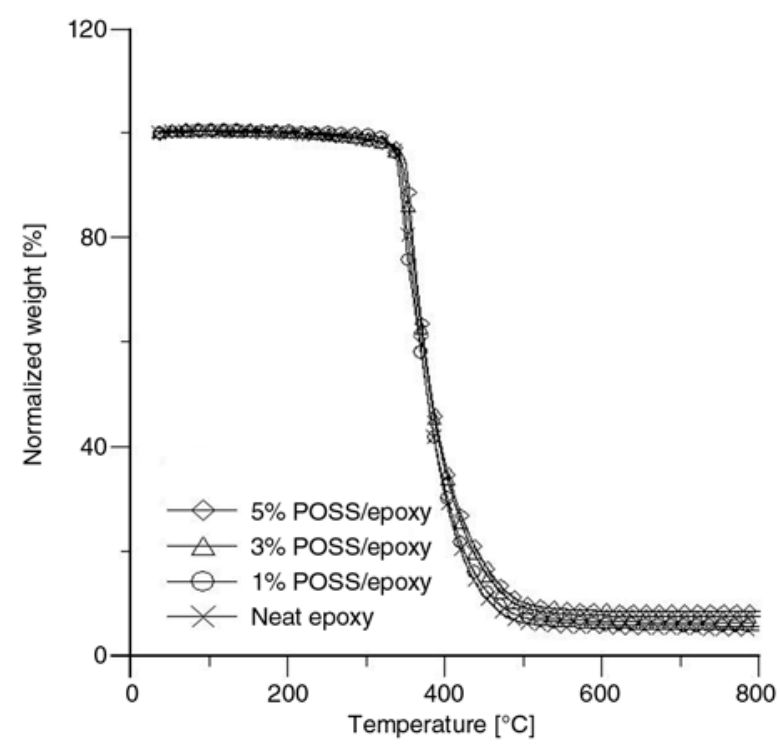

Figure 5. Weight loss versus temperature curves of POSS/epoxy nanocomposites

Figure 5 shows the normalized weights versus temperature curves of four materials. All samples began to decompose around $350^{\circ} \mathrm{C}$ and completely decomposed around $450^{\circ} \mathrm{C}$. This study considers the derivative peaks as the decomposition temperature. As shown in Figure 6, decomposition temperatures increased with higher POSS content. An increase of $10^{\circ} \mathrm{C}$ in decomposition temperature was

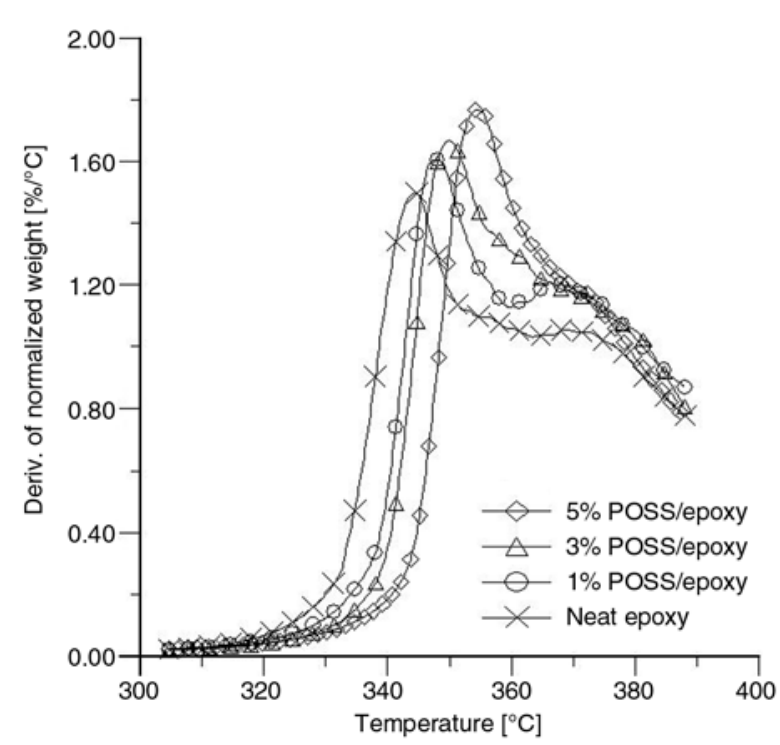

Figure 6. Effect of POSS content on thermal stability of epoxy observed in $5 \mathrm{wt} \%$ POSS/epoxy as compared with neat epoxy.

\subsection{Tensile properties}

Figure 7 shows the typical tensile stress-strain curves of neat and nanophased epoxy. The stressstrain curves show considerable nonlinearity before reaching maximum stress, which is assumed to be the yield strength of the material. After this point, stress decreased steadily with strain until fracture occurred. Five specimens were tested for each condition; the average properties obtained from these tests are listed in Table 1.

Figure 7 and Table 1 show that the yield strength and modulus of epoxy and POSS/epoxy nanocomposites increase continuously with increasing POSS content. 5\% POSS yielded a $16.6 \%$ increase in modulus and a $19.4 \%$ increase in yield strength. The small size of POSS, which restricts the mobility of polymer chains under loading, improved the modulus and yield strength; good interfacial adhesion between the POSS and matrix also contributed to the reinforcement [25]. Figure 8 represents the variation of modulus $E$ and yield strength $\sigma_{s}$ with the weight fraction of POSS as a linear relationship.

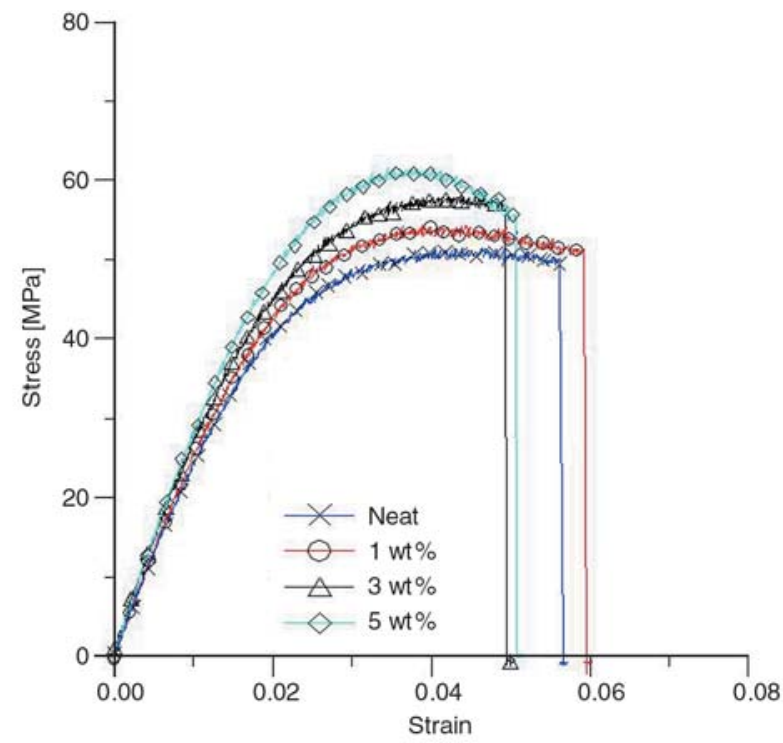

Figure 7. Tensile results of POSS/epoxy stress vs. strain curve

Table 1. Tensile properties of poss/epoxy nanocomposites

\begin{tabular}{|l|c|c|c|c|}
\hline \multicolumn{1}{|c|}{ Material } & Modulus [GPa] & Enhancement in modulus & Strength [MPa] & Enhancement in strength \\
\hline Neat epoxy & 2.59 & - & 51.5 & - \\
\hline $1 \mathrm{wt} \%$ POSS & 2.73 & $5.4 \%$ & 54.3 & $5.4 \%$ \\
\hline $3 \mathrm{wt} \%$ POSS & 2.77 & $6.9 \%$ & 57.9 & $12.4 \%$ \\
\hline $5 \mathrm{wt} \%$ POSS & 3.02 & $16.6 \%$ & 61.5 & $19.4 \%$ \\
\hline
\end{tabular}




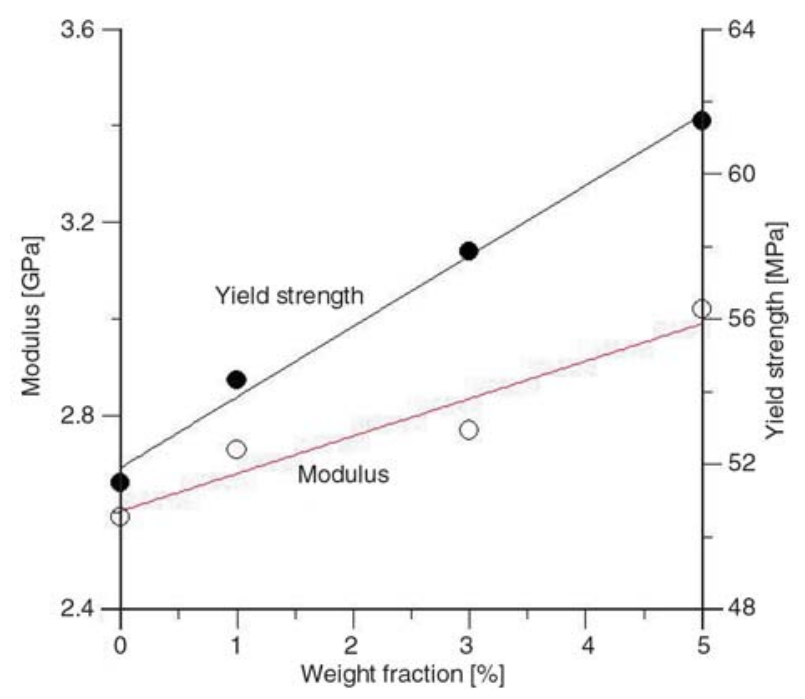

Figure 8. Effect of POSS weight fraction on modulus and yield strength of epoxy

Compared with multi-walled CNT-reinforced epoxy [28], vapor-grown CNF-reinforced epoxy [9], and nanoparticle-reinforced epoxy [29], no optimal loading was observed on the POSS/epoxy system, indicating good dispersion of POSS in epoxy. The Equations (1a) and (1b) fit the modulus and tensile strength data of the composite:

$$
\begin{aligned}
& E=E_{0}+m_{1} w_{p} \\
& \sigma_{s}=\sigma_{s 0}+m_{2} w_{p}
\end{aligned}
$$

where $E_{0}$ and $\sigma_{s 0}$ are reference elastic modulus and reference yield strength, and $w_{p}$ is the weight fraction of POSS. Two other parameters, $m_{1}$ and $m_{2}$, appearing in Equations (1a) and (1b), represent weight fraction strengthening coefficients for modulus and tensile strength, respectively. Mathematically, they are defined by Equation (2):

$$
m_{1,2}=\frac{\partial\left(E, \sigma_{s}\right)}{\partial w_{f}}
$$

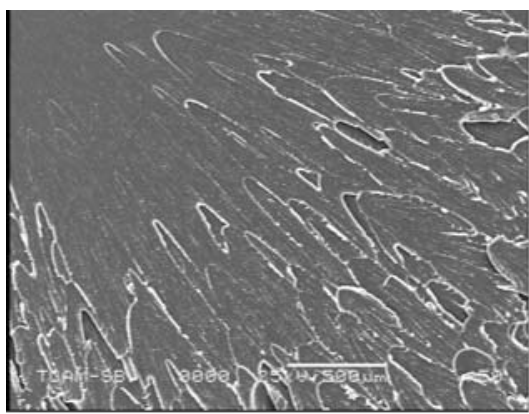

a)

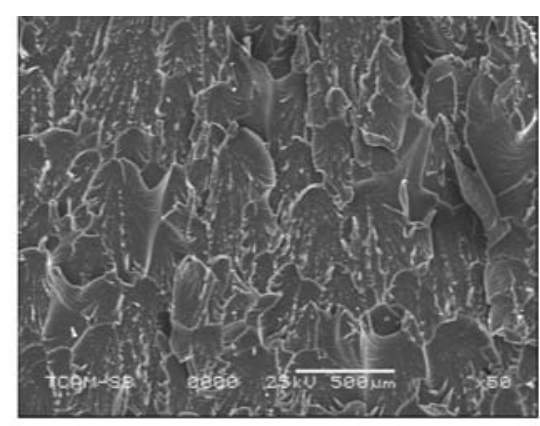

b)
Using the least square method, the $m$ values of the composite were calculated as shown by Equations (3a) and (3b):

$$
\begin{aligned}
& \sigma_{s}=51.9+194.4 W \quad[\mathrm{MPa}] \\
& E=2.60+7.7 W \quad[\mathrm{GPa}]
\end{aligned}
$$

\subsection{Fracture surfaces}

The fracture surfaces of neat epoxy and the nanocomposites were compared using SEM. Figure 9a shows that neat epoxy resin exhibits a relatively smooth fracture surface and that the initial crack occurred at the tension edge of the specimen. The river pattern in Figure 9a indicates a typical cleavage fracture, accounting for the low fracture toughness of the unfilled epoxy. Compared to neat epoxy, the fracture surfaces of the nanocomposites show considerably different fractographic features. For example, the failure surfaces of the nanocomposites containing $1 \mathrm{wt} \%$ POSS and $5 \mathrm{wt} \%$ POSS are shown in Figure $9 \mathrm{~b}$ and 9c. Generally, adding POSS into the epoxy matrix results in a much rougher fracture surface and the surface roughness increases with higher POSS content.

The higher magnification micrographs of POSS/ epoxy nanocomposites are shown in Figure 10a (for 1\% POSS/epoxy) and Figure 10b (for 5\% POSS/epoxy). The rougher fracture surface consists of many small smooth zones. These smooth zones nucleate in the material at areas of localized deformation and, in the center of each partly ovalshaped zone, a second-phased particle can be observed, as shown in Figure 10c. During the failure process, the crack propagation changed direction as it crossed second-phased particles. The pinning effect, which prevents crack opening,

Figure 9. Fracture surface of neat and nanophased epoxy (a - neat epoxy; b - 1 wt \%POSS/epoxy and c - 5 wt $\%$ POSS/epoxy) 


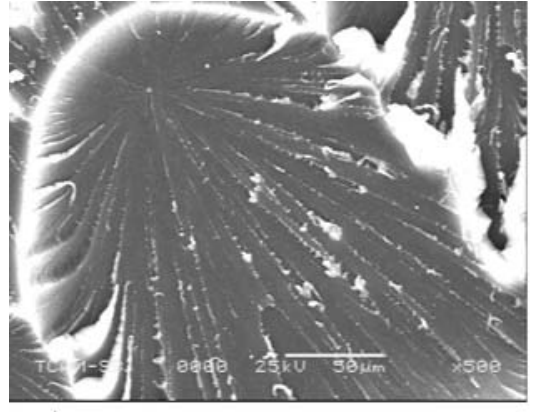

a)

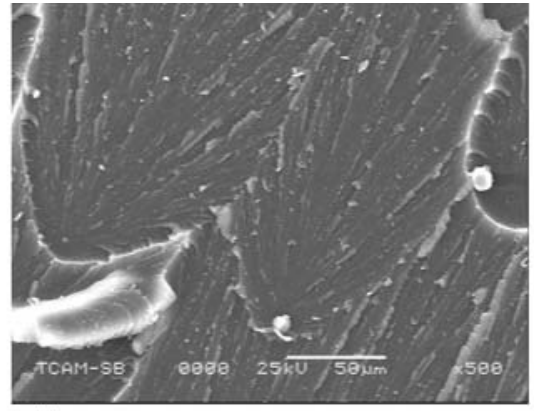

b)

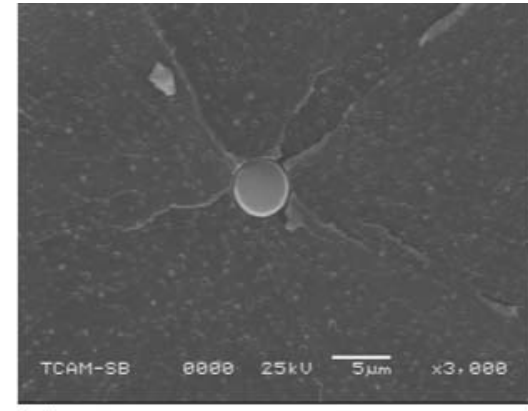

c)

Figure 10. Fracture surface of POSS/epoxy nanocomposite ( $a$ - large smooth zone in 1\% POSS/epoxy; $b$ - small smooth zone in 5\% POSS/epoxy and c - second-phased particle in the center of smooth zone)

increased the strength of the epoxy. The size of the smooth zones on a fracture surface is determined by the number and distribution of second-phased particles. When second-phased parties are few and widely spaced, the cracks propagate longer before coalescing, resulting in a fracture surface with large smooth zones. Smaller zones are formed when many second-phased particles are produced. Figures $10 \mathrm{a}$ and $10 \mathrm{~b}$ show that the size of smooth zones decreases with increasing POSS weight fractions. Fewer smooth zones and more surface roughness imply that the number of second-phased particles increased with increasing POSS content. The path of the crack tip is distorted because of more second-phased particles, which make crack propagation more difficult.

\subsection{Constitutive equation}

The failure of fiber reinforced epoxy involves a complicated damage accumulation process resulting from random fiber breakage, stress transfer form fiber to matrix, and interface debonding between the fiber and matrix. It is necessary to obtain stress strain relationship of matrix to analyze such a complicated probabilistic failure phenomenon. To better understand the stress-strain relationship of neat and nanophased epoxy, a nonlinear constitutive equation has been developed. In the proposed constitutive model (Equation (4)), the total strain is assumed to be composed of an elastic part and an inelastic part:

$\varepsilon=\varepsilon_{e}+\varepsilon_{i}$

where $\varepsilon_{e}$ and $\varepsilon_{i}$ represent the elastic and inelastic strains, respectively. The elastic strain is assumed to be path-independent and related to the elastic modulus of the material. It is expressed by Equation (5):

$\varepsilon_{e}=\frac{\varepsilon}{E}$

where $E$ is the elastic modulus of the POSS/epoxy material, which is a function of both strain rate and temperature, and where $\sigma$ is the stress. The inelastic strain, $\varepsilon_{i}$, is assumed to be a function of both stress and strain, as shown by Equation (6):

$\varepsilon_{i}=\beta \sigma \varepsilon^{m}$

where $\beta$ represents a compliance parameter and $m$ is a strain exponent. Therefore, by substituting Equations (5) and (6) into Equation (4) and rearranging, we obtain the Equation (7):

$$
\sigma=\frac{E \varepsilon}{1+E \beta \varepsilon^{m}}
$$

To determine the material parameters in the constitutive equation, Equation (7) is rewritten into Equation (8):

$$
\frac{\varepsilon}{\sigma}-\frac{1}{E}=\beta \varepsilon^{m}
$$

This equation, on taking log on both sides, transforms into Equation (9):

$\ln \left(\frac{\varepsilon}{\sigma}-\frac{1}{E}\right)=\ln \beta+m \ln \varepsilon$

Equation (9) represents a linear plot of $\ln [\varepsilon / \sigma-1 / E]$ versus ln $\varepsilon$. The slope of the linear plot is $m$ and the intercept at $\varepsilon=1$ is $\ln \beta$. These linear plots at different strain rates are nearly parallel to each other, which means that the material has the same strain 


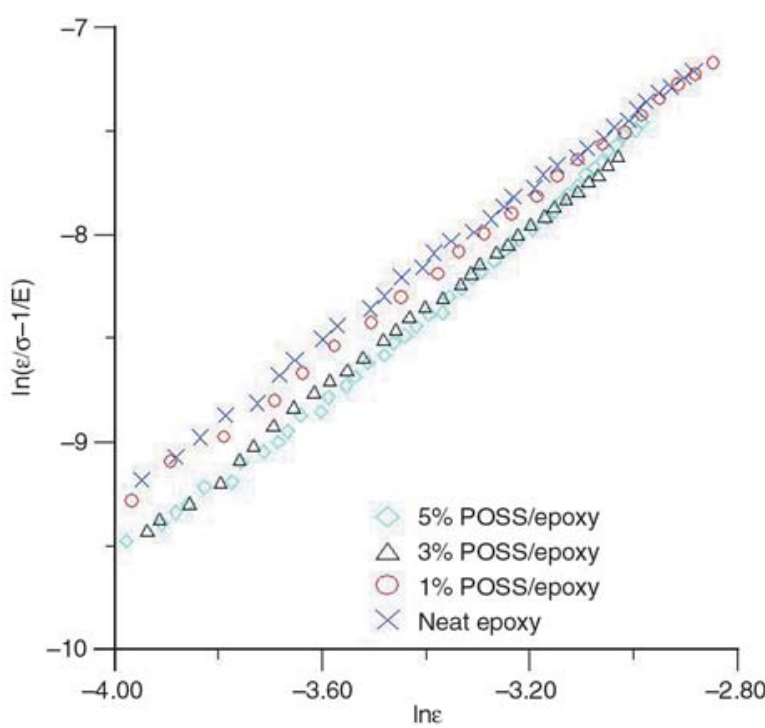

Figure 11. The plot of $\ln [\varepsilon / \sigma-1 / E]$ vs. $\ln \varepsilon$ of materials

exponent at different test conditions. The plots of $\ln [\varepsilon / \sigma-1 / E]$ versus $\ln \varepsilon$ of neat epoxy and POSS/ epoxy is shown in Figure 11. The compliance factor $\beta$ and strain exponent $m$ obtained from these plots are plotted as a function of POSS content in Figure 12. Also, strain exponent $\mathrm{m}$ and compliance factor expressed as functions of POSS content are as follows. See Equations (10a) and (10b), respectively:

$m=1.85+4.5 W$

$\beta=0.150+2.40 W \quad[1 / \mathrm{MPa}]$

As shown in Figure 13, elastic modulus $E$, compliance factor $\beta$, and strain exponent $m$ in Equa-

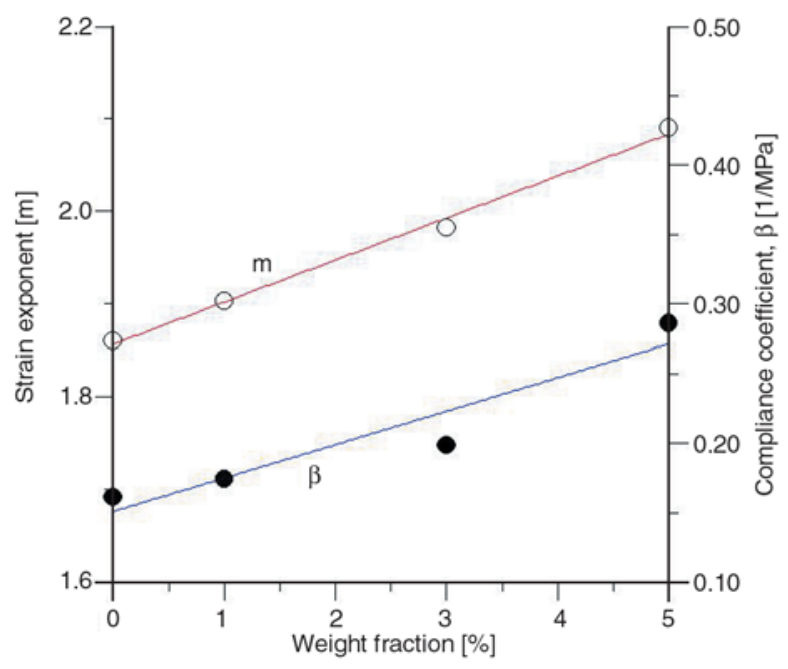

Figure 12. Compliance factor $\beta$ and strain exponent $m$

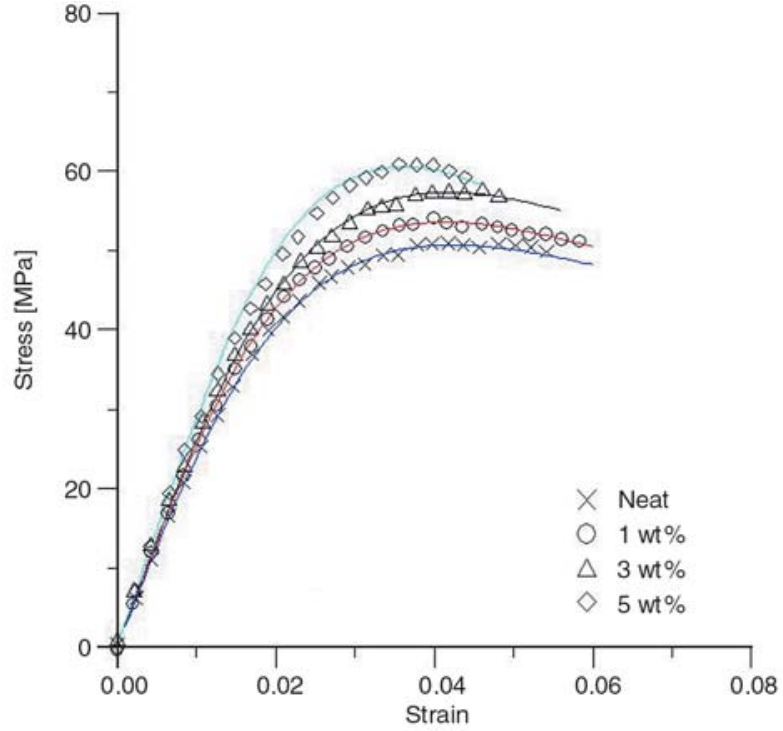

Figure 13. Comparison between experiment results and simulated results

tion (7), the simulated stress-strain plots fit the experiment data very well.

\section{Conclusions}

1. DMA results exhibited a $16^{\circ} \mathrm{C}$ increase in $T_{g}$ in $5 \mathrm{wt} \%$ POSS/epoxy as compared with neat epoxy.

2. TGA results show that the POSS content has successfully increased the decomposition temperature as well.

3. The tensile results indicate that $5 \mathrm{wt} \%$ loading of POSS in epoxy resin showed the highest improvement in the tensile strength as compared to the neat systems. Also, there was an improvement in the elastic modulus.

4. The nonlinear constitutive equation established in this study can predict the stress-strain tensile behavior of the POSS/epoxy nanocomposite.

\section{Acknowledgements}

The authors would like to gratefully acknowledge the support of the National Science Foundation.

\section{References}

[1] Donnet J. B.: Nano and microcomposites of polymers elastomers and their reinforcement. Composites Science and Technology, 63, 1085-1088 (2003).

[2] Zheng Y., Zheng Y., Ning R.: Effects of nanoparticles $\mathrm{SiO}_{2}$ on the performance of nanocomposites. Materials Letters, 57, 2940-2944 (2004). 
[3] Day R. J., Lovell P. A., Wazzan A. A.: Toughened carbon/epoxy composites made by using core/shell particles. Composites Science and Technology, 61, 41-56 (2001).

[4] Bagheri R., Pearson R. A.: Role of particle cavitation in rubber-toughened epoxies: II. Inter-particle distance. Polymer, 41, 269-276 (2001).

[5] Kumar K. D., Kothandaraman B.: Modification of (DGEBA) epoxy resin with maleated depolymerised natural rubber. Express Polymer Letters, 2, 302-311 (2008).

[6] Zhou Y. X., Wu P. X., Cheng Z-Y., Ingram J., Jeelani S.: Improvement in electrical, thermal and mechanical properties of epoxy by filling carbon nanotube. Express Polymer Letters, 2, 40-48 (2008).

[7] Chisholm N., Mahfuz H., Rangari V. K., Ashfaq A., Jeelani S.: Fabrication and mechanical characterization of carbon/SiC-epoxy nanocomposites. Composite Structures, 67, 15-124 (2005).

[8] Gojny F. H., Wichmann M. H. G., Fiedler B., Bauhofer W., Schulte K.: Influence of nano-modification on the mechanical and electrical properties of conventional fibre-reinforced composites. Composites, Part A: Applied Science and Manufacturing, 36, 1525-1535 (2005).

[9] Pervin F., Zhou Y., Rangari V., Jeelani S.: Testing and evaluation on the thermal and mechanical properties of carbon nano fiber reinforced SC-15 epoxy. Materials Science and Engineering, Part A, 405, 246-253 (2005).

[10] Zhou Y., Pervin F., Biswas M. A., Rangari V., Jeelani S.: Fabrication and characterization of montmorillonite clay-filled SC-15 epoxy. Materials Letters, 60, 869-873 (2006).

[11] Auad M. L., Nutt S. R., Pettarin V., Frontini P. M.: Synthesis and properties of epoxy-phenolic clay nanocomposites. Express Polymer Letters, 1, 629-639 (2007).

[12] Reynaud E., Gauthier C. Perez J.: Nanophases in polymers. Review Metallurgie, 96, 169-176 (1999).

[13] Haddad T. S., Stapleton R., Jeon H. G., Mather P. T., Lichtenhan J. D., Phillips S.: Nanostructured hybrid organic/inorganic materials. Silsesquioxane modified plastics. Polymer Preprints, 40, 496-497 (1999).

[14] Lee A., Lichtenhan J. D.: Thermal and viscoelastic property of epoxy-clay and hybrid inorganic-organic epoxy nanocomposites. Journal of Applied Polymer Science, 73, 1993-2001 (1999).

[15] Fina A., Tabuani D., Frache A., Camino G.: Polypropylene-polyhedral oligomeric silsesquioxanes (POSS) nanocomposites. Polymer, 46, 7855-7866 (2005).

[16] Fina A., Abbenhuis H. C. L., Tabuani D., Frache A., Camino G.: Polypropylene metal functionalised POSS nanocomposites: A study by thermogravimetric analysis. Polymer Degradation and Stability, 91, 10641070 (2006).
[17] Mulliken A. D., Boyce M. C.: Polycarbonate and a polycarbonate-POSS nanocomposite at high rates of deformation. Journal of Engineering Materials and Technology, 128, 543-550 (2006).

[18] Zhao Y., Schiraldi D. A.: Thermal and mechanical properties of polyhedral oligomeric silsesquioxane (POSS)/polycarbonate composites. Polymer, 46, 11640-11647 (2005).

[19] Ramasundaram S. P., Kim K. J.: In-situ synthesis and characterization of polyamide 6/POSS nanocomposites. Macromolecular Symposia, 249-250, 295-302 (2007).

[20] Baldi F., Bignotti F., Ricco L., Monticelli O., Ricco T.: Mechanical and structural characterization of POSS-modified polyamide 6. Journal of Applied Polymer Science, 100, 3409-3414 (2006).

[21] Matejka L., Strachota A., Plestil J., Whelan P., Steinhart M., Šlouf M.: Epoxy networks reinforced with polyhedral oligomeric silsesquioxanes (POSS): Structure and morphology. Macromolecules, 37, 94499456 (2004).

[22] Strachota A., Kroutilova I., Kovarova J., Matejka L.: Epoxy networks reinforced with polyhedral oligomeric silsesquioxanes (POSS). Thermomechanical properties. Macromolecules, 37, 9457-9464 (2004).

[23] Fu B., Namani M., Lee A.: Influence of phenyl-trisilanol polyhedral silsesquioxane on properties of epoxy network glasses. Polymer, 44, 7739-7747(2003).

[24] Liu Y., Zheng S., Nie K.: Epoxy nanocomposites with octa(propylglycidyl ether) polyhedral oligomeric silsesquioxane. Polymer, 44, 12016-12025 (2005).

[25] Dodiuk H., Kening S., Blinsky I., Dotan A., Buchman A.: Nanotailoring of epoxy adhesives by polyhedraloligomeric-sil-sesquioxanes (POSS). International Journal of Adhesion and Adhesives, 25, 211-18 (2005).

[26] Liu H. Z., Zhang W., Zheng S. X.: Montmorillonite intercalated by ammonium of octaaminopropyl polyhedral oligomeric silsesquioxane and its nanocomposites with epoxy resin. Polymer, 46, 157-165 (2005).

[27] Huang J-C., He C-B., Xiao Y., Mya K. Y., Dai J., Siow Y. P.: Polyimide/POSS nanocomposites: Interfacial interaction, thermal properties and mechanical properties. Polymer, 44, 4491-4499 (2003).

[28] Zhou Y., Pervin F., Lewis L., Jeelani S.: Experimental study on the thermal and mechanical properties of multi-walled carbon nanotube-reinforced epoxy. Materials Science and Engineering, Part A: Structural Materials: Properties, Microstructure and Processing, 452-453, 657-664 (2007).

[29] Rodgers R., Mahfuz H., Rangari V. K., Chisholm N., Jeelani S.: Infusion of $\mathrm{SiC}$ nanoparticles into SC-15 epoxy: An investigation of thermal and mechanical response. Macromolecular Materials and Engineering, 290, 423-429 (2005). 